\title{
Evaluation of Soil Erosion Using 3S Techniques: A Case Study of Cangxi County in the Jialing River Basin, Yangtze River, China
}

\author{
Yijin Wu ${ }^{1,2}$, Wenna $\mathrm{Tu}^{2}$, Yue $\mathrm{Xi}^{2}$, Jing Hu${ }^{1,2,3}$, Chang $\mathrm{Li}^{1,2}$ \\ ${ }^{1}$ Key Laboratory for Geographical Process Analysis \& Simulation, Central China Normal University \\ Hubei Province, Wuhan, China \\ ${ }^{2}$ College of Urban and Environmental Science, Central China Normal University \\ Wuhan, China \\ ${ }^{3}$ Wuhan Branch of China Tourism Academy \\ Wuhan, China \\ lcshaka@126.com; lichang@mail.ccnu.edu.cn
}

\begin{abstract}
Soil erosion not only has a negative impact on the ecological environment, but also restricts the sustainable development. Therefore, it's significant to develop green ecology, evaluate soil erosion in large river valley, and propose feasible suggestions of soil and water conservation. This paper uses 3S technology to evaluate soil erosion of Cangxi County in the Jialing River basin, Yangtze River, China. The main steps include: (1)Image pre-processing: using ZY-3 and GF-1 satellite data, both geometric error and radiometric error are corrected so that image accuracy is improved; (2)Field investigation and indoor interpretation of remote sensing: field interpretation marks are established by GPS and RS; mainly image interpretation is carried out by machine learning or image classification, then results are checked by visual interpretation and confirmed by field review to improve interpretation accuracy; (3)Spatial analysis: soil erosion intensity is classified and soil erosion intensity map can be obtained through "standards for classification and gradation of soil erosion"(SL190-2007) based on three factors(land-use types, vegetation coverage and slope); (4)soil erosion evaluation: soil erosion is evaluated by soil erosion intensity map. The results show that: (1)The intensity of soil erosion in the study area is concentrated on slight and moderate soil erosion; the area with severe soil erosion is few; (2)The soil erosion of townships are mainly concentrated on the north and east of the county, while soil erosion is relatively slight in the northwest and southwest; (3) Under the influence of different factors, the soil erosion intensity is quite different and is often affected by many factors(exposed soil, human activities). Finally, this paper proposes some specific measures from the perspective of green ecology, which may provide a view to a certain reference for soil and water conservation in the study area and evaluation of soil erosion in other regions in Yangtze River, China.
\end{abstract}

Keywords: Soil erosion, Sustainable development, 3S (RS, GIS, GPS) technology, Yangtze River.

\section{Introduction}

Soil erosion, as an important environmental issue facing the world today, has a more serious negative impact on the ecological environment and social economy, attracting the attention of scholars all over the world and has formed rich research results. In the traditional empirical model, Wischmeier and Smith constructed a universal soil loss equation. It has been rapidly promoted and applied in the United States and even in the world[1]and[2] . Renard proposed to modify the general soil erosion equation[3]. Liu Baoyuan constructed the Chinese soil loss equation[4]. In terms of physical models, representative models include European EU-ROSEMHE[5] and LISEM[6], and Australian GUEST[7]. With the development of RS (Remote sensing) and GIS (Geographic information system) technology, its advantages are also revealed in the study of soil erosion[8] and[9]. Chinese scholars have also done extensive research on this topic[10],[11] and[12]. President Xi Jing Ping emphasized that the Yangtze River is the mother river of the Chinese nation and an important support for the development of the Chinese nation. To promote the development of the Yangtze River Economic Belt, we must take eco-priority and green development roads, so that the mother river will remain viable. Therefore, exploring and applying $3 \mathrm{~S}$ technology to evaluate and analyze the status of soil erosion has important practical significance.

This article use the " $3 \mathrm{~S}$ " technology to evaluate soil erosion in Cangxi County in the Jialing River Basin, Yangtze River and analyze the spatial distribution characteristics of soil erosion, providing scientific reference for the treatment and decision-making of soil erosion in the region and even other regions. 


\section{Research Areas and Data Sources}

\subsection{Regional Overview}

Cangxi County belongs to Guangyuan City, Sichuan Province, which is located on the middle reaches of the Jialing River; the whole territory is located at latitudes $31^{\circ} 37^{\prime}-32^{\circ} 10^{\prime} \mathrm{N}$ and $105^{\circ} 43^{\prime}-106^{\circ} 28^{\prime} \mathrm{E}$ (Fig. 1), soil erosion in the study area was aggravated. Therefore it is of theoretical and practical significance to evaluate soil erosion in Cangxi County.

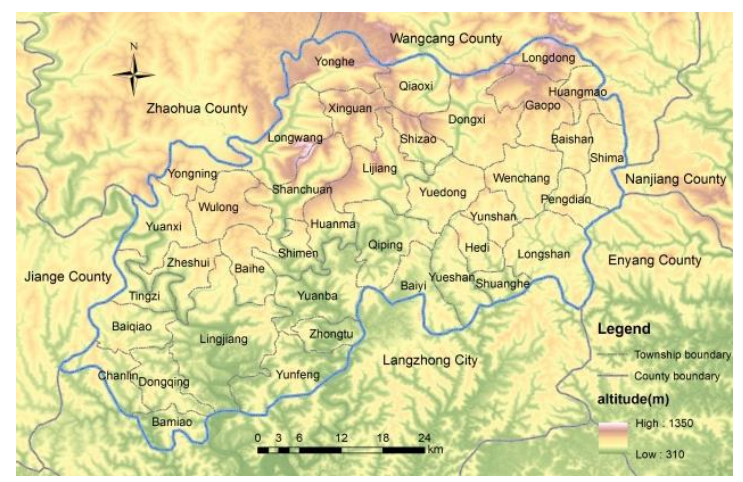

Fig. 1: The study area.

\subsection{Sources of Data}

The DEM data of this study are sourced from Chinese Academy of Sciences with a spatial resolution of $30 \mathrm{~m}$. Remote sensing imagery data are mainly synthesized by four scenes of the ZY-3 from November 2014 to February 2015, of which the spatial resolution is $2.5 \mathrm{~m}$. The image imaging period is generally in winter, basically with no cloud coverage. In addition, GF-1 satellite data are used as a supplement to improve image accuracy. In order to improve the interpretation accuracy, the research team conducted two field investigations in the study area in July and October 2015, to establish interpretation signs and review.

\section{Methods}

(1) Image preprocessing. After radiation correction, geometric correction, et al, the ZY-3 image quality can meet the interpretation requirements. The image misalignment is basically controlled within 4 pixels, reaching the correlation technical specification requirements of soil erosion evaluation. (2) Field investigations and establishment of interpretation signs. Field surveys are mainly based on routine surveys. The fixed-points are determined by GPS in typical areas, image interpretation mark survey form is filled out, and relevant information is record. (3) Indoor interpretation. The interpretation of remote sensing image is mainly based on the image features of ground objects type. Machine learning methods (random forest) are used to initially classify objects, and visual interpretation methods are used as an aid to correct error topology and confirm attributes. (4) Field review. It mainly adopts random sampling method and typical area fixed-point inspection method, through GPS positioning or manual accurate positioning. The map spots are verified one by one to improve the image interpretation accuracy. (5) Review and modification: according to the field review, the attributes of the map spot with errors are corrected. (6) Spatial analysis. Using the three types of land use types, vegetation coverage from remote sensing images and slopes extracted by DEM, comprehensively, the soil erosion map is determined. Then the paper explores the characteristics and causes of spatial distribution. 


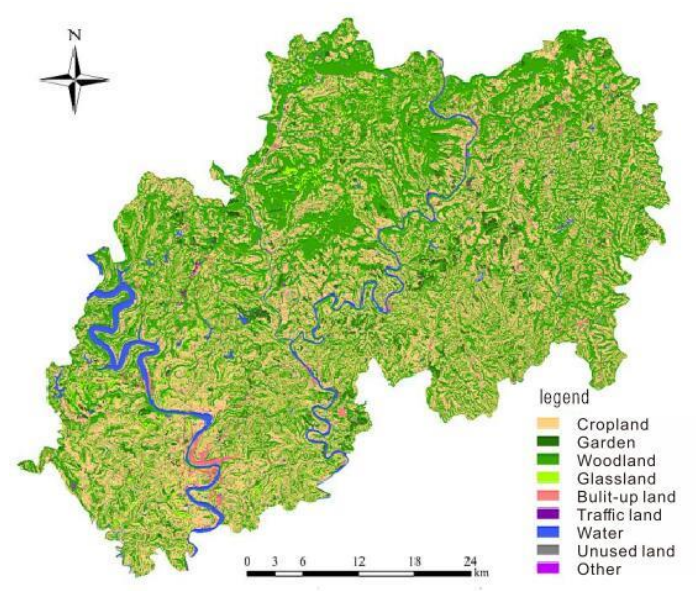

Fig. 2: the map of land use types.

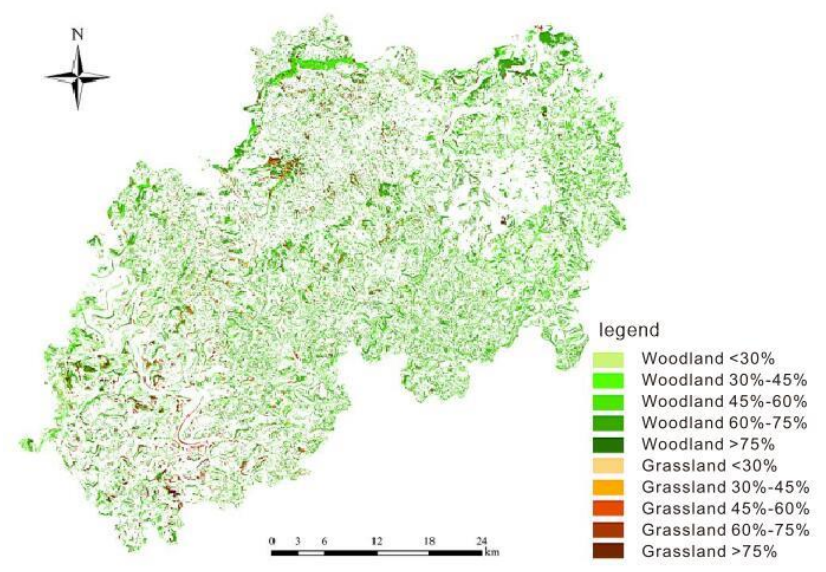

Fig. 3: the map of vegetation coverage rating.

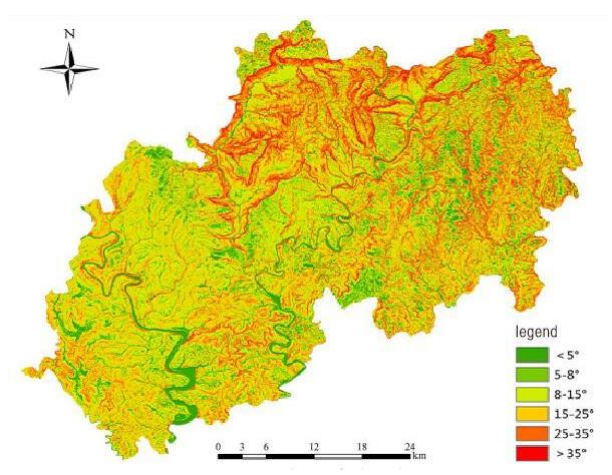

Fig. 4: the map of vegetation coverage rating.

After the above steps, this paper gets the land use classification map of the study area (Fig. 2). Though "Technical specification of soil and water conservation monitoring by remote sensing" (SL592-2012), the vegetation coverage are divided into 5 grades $(<30 \%, 30 \%-45 \%, 45 \%-60 \%, 60 \%-75 \%$, and $>75 \%)$ (Fig. 3).Using DEM as the data source, the slope gradient is divided into 6 grades $\left(<5^{\circ}, 5-8^{\circ}, 8-15^{\circ}, 15-25^{\circ}, 25-35^{\circ}\right.$, and $\left.>35^{\circ}\right)$ (Fig. 4$)$.

According to requirements in SL592-2012, the number of actual inspection map spot is not less than 1\%, and the area is not less than $5 \%$. The area reviewed in this study accounted for 5.05\% of the total area, and the number of map spots accounted for $2.19 \%$ of the total number of spots. The area verification rate of the sample point is $92.54 \%$, and the spot 
verification rate is $91.51 \%$. It can reflect that the interpretation of data is basically in line with the situation on the ground, and the interpretation accuracy can meet the needs of research.

Based on "standards for classification and gradation of soil erosion"(SL190-2007), combined with the analysis of the soil erosion in the study area, this paper determine the classification criteria for soil erosion (Table 1), soil erosion intensity map is obtained (Fig. 5).

Table 1: "standards for classification and gradation of soil erosion" (SL190-2007).

\begin{tabular}{cccccccc}
\hline \multirow{2}{*}{ Land use } & $\begin{array}{c}\text { Forest cover } \\
(\%)\end{array}$ & $<5^{\circ}$ & $5-8^{\circ}$ & $8-15^{\circ}$ & $15-25^{\circ}$ & $25-35^{\circ}$ & $>35^{\circ}$ \\
& $>75$ & Slight & Slight & Slight & Slight & Slight & Slight \\
& $60-75$ & Slight & Micro & Micro & Micro & Moderate & Moderate \\
& $45-60$ & Slight & Micro & Micro & Moderate & Moderate & Severe \\
Woodland and Grassland & $30-45$ & Slight & Micro & Moderate & Moderate & Severe & Violent \\
& $<30$ & Slight & Moderate & Moderate & Severe & Violent & Extremly violent \\
\hline Cropland & & Slight & Micro & Moderate & Severe & Violent & Extremly violent \\
Garden & & Slight & Slight & Micro & Moderate & Severe & Violent \\
Bulit-up land & & Slight & Slight & Slight & Slight & Slight & Slight \\
Traffic land & & Slight & Slight & Slight & Slight & Slight & Slight \\
Other & & Slight & Micro & Moderate & Severe & Violent & Extremly violent \\
\hline & & & & & & &
\end{tabular}

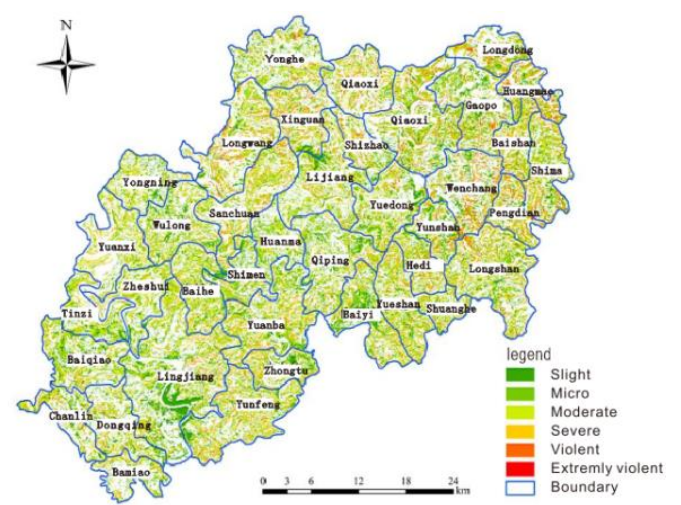

Fig. 5: the map of soil erosion intensity distribution.

\section{Results}

\subsection{Soil Erosion Intensity}

(1) General characteristics

In soil erosion intensity, the soil erosion in the study area was serious overall. The proportions of soil erosion with micro, moderate, and severe intensity accounted for $21.31 \%, 30.52 \%$, and $21.78 \%$, respectively; the violent intensity accounted for $6.17 \%$; the extremely violent intensity accounted for $0.75 \%$. It can be seen that the erosion intensity in the study area is concentrated on the moderate soil erosion, followed by the severe, slight and micro soil erosion, while the ratio of violent and extremely violent soil erosion is relatively low. Therefore, slight, moderate, and severe intensity are the main types of soil erosion in the study area, and their governance can effectively alleviate the serious situation of soil erosion. 
Table 2: Soil erosion area statistics.

\begin{tabular}{cccc}
\hline Soil erosion level & Area $\left(\mathrm{km}^{2}\right)$ & Ratio of total area of soil erosion (\%) & Ratio of total land area (\%) \\
\hline Slight & 235.29 & 21.31 & 10.09 \\
Micro & 214.97 & 19.47 & 9.23 \\
Moderate & 337.09 & 30.52 & 14.47 \\
Severe & 240.61 & 21.78 & 10.33 \\
Violent & 68.11 & 6.17 & 2.92 \\
Extremly violent & 8.29 & 0.75 & 0.35 \\
Total & 1104.36 & 100 & 47.39 \\
\hline
\end{tabular}

(2) Spatial distribution characteristics

In terms of spatial distribution, the serious soil erosion of townships is mainly distributed in the north, central and east of the county, while townships in the northwest and southwest have relatively slight soil erosion. In Cangxi County, there are 14 townships where soil erosion rate are all above 50\%, such as Baishan, Baiduo, Yueshan, at el. About 8 townships' soil erosion rate are basically around $40 \%$ or below. Such as Dongqing, Yongning, Shizao; the remaining other townships have the moderate soil erosion intensity, which is between $40 \%$ and $50 \%$.

The causes of soil erosion in the above 14 townships are as follows: the Weihe rivers in the northern and Baishan, Baiduo, Yueshan, Shima, Hedi, Yunshan, Pengdian, Shuanghe, Huangcao and Longshan in southeastern have relatively high altitude, steep slopes and large-scale reclamation of cultivated land and orchards, which cause soil erosion. Baihe, Zhongtu and Yuanba in the central and southern parts of Cangxi country, the three townships are low-lying, but there are many manmade production and construction activities, leading to serious soil erosion in the region.

\subsection{Impact Factor Correlation Analysis}

(1) Vegetation factors

Vegetation has the function of conserving water source and consolidating soil. Good vegetation coverage can effectively reduce surface runoff, and to some extent inhibit the occurrence of soil erosion. The area with $60 \%-75 \%$ vegetation coverage is the largest, accounting for $41.11 \%$ of the total area of soil erosion, followed by the area with $45 \%-60 \%$ vegetation coverage, accounting for $40.65 \%$ of the total area of soil erosion. This is due to the fact that the area with both the two vegetation coverage rate accounted for most of the area in the study area. In addition, under the influence of hilly terrain and surface exposed under the vegetation, the area of soil erosion is relatively large. However, in view of the intensity of erosion, erosion intensity is mostly dominated by slight, micro and moderate erosion, and the amount of soil erosion per unit area is small. The soil erosion area with $30 \%-45 \%$ vegetation coverage is relatively small and the soil erosion area with $<30 \%$ vegetation coverage is the smallest, accounting for only $0.69 \%$ of the total soil erosion area. This is due to the fact that the two types of vegetation coverage in the study area are small. And violent and extremely violent erosion are mainly distributed at $<30 \%$ vegetation coverage level and the amount of soil erosion is large per unit area.

(2) Land use factor

Different types of land use itself lead to greater differences in soil erosion. Soil and water loss in the region mainly occurs in arable land and natural woodland where human activities are strongly negatively affected. The soil erosion area of cropland accounts for $47.92 \%$ of the total area of soil erosion in the entire study area, followed by woodland, which is accounting for $29.28 \%$. The main reason is that there are many farmland areas in slope and the soil and water conservation capacity is poor under the influence of human farming activities. Although woodland is better for soil and water conservation due to its vegetation cover and less human interaction, the actual field investigation found that the study area was covered with high vegetation while there were many exposed soils below the woodland. The lack of protection of soil erosion by vegetation shrubs, combined with the topographic effects of mountainous terrain, results in a relatively large area of soil erosion.

(3) Terrain Factors

The differences in elevation, slope, etc. have a great impact on the speed and intensity of soil erosion. From the aspect of soil erosion and terrain correlation analysis, the area of soil erosion in the study area is mainly distributed in mountainous 
regions with altitudes of $450-600 \mathrm{~m}$ and $600-750 \mathrm{~m}$, accounting for $65.42 \%$ of the total area of soil erosion; the topography of the area is mainly mountainous. Due to the main production activities in study area are ploughing agriculture, the slope is large in this elevation range, in addition, there are many disturbances to the surface by human activities, and the intensity of land use development is relatively large, results in a large area of soil erosion.

Soil erosion is severe and erosion intensity is mainly based on severe, violent and extremely violent, where the slopes are mainly concentrated in the areas within the range of $8-15^{\circ}, 15-25^{\circ}$, and $25-35^{\circ}$, accounting for $39.57 \%, 28.59 \%$, and $13.54 \%$ of the total area of soil erosion, respectively. Therefore, in the future, the focus of soil and water conservation should be on the areas with an altitude of $450 \mathrm{~m}-750 \mathrm{~m}$ and a slope of $8-35^{\circ}$.

\section{Prevention Measures}

Based on the analysis of the above evaluation results, there are several specific measures:

1) To control soil erosion comprehensively according to local conditions

Cangxi County should seize the opportunity of prevention and control as a key treatment area for soil erosion at the national level. Actively implement the return of farmland to forests, slope change ladder, accelerate the adjustment of industrial structure so as to achieve the unity of ecological, economic, and social benefits.

2) Unified planning, implementation of partition prevention

Based on the status quo of soil erosion, geographical distribution and spatial distribution of the soil erosion in the study area, combined with the natural socio-economic development of Cangxi County, the prevention and control of soil erosion in the study area is planned and divided into three grades to take appropriate measures to focus on the purpose of governance.

3) Strengthen rural energy development and optimize energy structure

Cangxi County has a large area of mountainous area and has a large rural population. It has been burning firewood as the main energy source, resulting in excessive cutting of trees and serious soil erosion. Therefore, we should actively guide farmers in areas with severe soil erosion to take advantage of rural crop stalks, livestock and manure, and vigorously develop biogas digesters. In addition, when developing and utilizing the abundant natural gas resources of Cangxi County, it actively covers the vast rural areas and provides clean energy and a good living environment for the majority of farmers.

4) Establish sound water and soil conservation monitoring and forecasting system

Strengthen the construction of soil and water conservation monitoring facilities, actively promote the application of " $3 \mathrm{~S}$ " technology in soil and water conservation monitoring, and establish soil and water conservation monitoring information system. Provide scientific reference for the planning and management of soil and water conservation in Cangxi County.

\section{Conclusion}

(1) This study gives full play to the advantages of integrated application of $3 \mathrm{~S}$ technology, uses $3 \mathrm{~S}$ technology to carry out field investigations to establish interpretation marks and verification, and completes the main tasks of indoor interpretation.

(2) The monitoring results show that, the proportions of soil erosion with slight, moderate, severe intensity accounted for $21.31 \%, 30.52 \%$, and $21.78 \%$, respectively; the violent intensity accounted for $6.17 \%$; the extremely violent intensity accounted for $0.75 \%$. Therefore, slight, moderate, and severe erosion are the main types of soil erosion in the study area, and their governance can effectively alleviate the serious situation of soil erosion, which is of great significance for the soil and water conservation in the study area.

(3) From the perspective of spatial distribution, there is a certain difference in soil erosion intensity in the study area. Townships with more serious losses are mainly distributed in the northern, central and eastern, while townships in the northwest and southwest have relatively less soil erosion. The rate of soil erosion in 14 townships in the southeast is above $50 \%$. Western townships have relatively small soil erosion, and the loss rate is basically around $40 \%$ and below. The loss rate of the rest of the other townships is between $40 \%$ and $50 \%$.

(4) According to the correlation analysis of soil erosion and vegetation coverage, the soil erosion in the study area is mainly concentrated in the vegetation coverage range of $60 \%-75 \%$ and $45 \%-60 \%$, and the resulting soil erosion area is relatively large, but the erosion intensity is mostly slight, micro and moderate, and the amount of soil erosion per unit area was relatively small. It is the key treatment area for soil erosion afterwards. 
(5) According to the correlation analysis of soil erosion and land use, the soil erosion in the region mainly occurs in the arable land and natural woodland where human activities are strongly disturbed. The soil erosion area of cultivated land accounted for $47.92 \%$ of all the lost areas, followed by forest land, accounting for $29.28 \%$, accounting for $77.20 \%$ of the total.

(6) According to the correlation analysis of soil erosion and topography, the area of soil erosion is mainly distributed in mountainous regions with an altitude of $450-600,600-750 \mathrm{~m}$, accounting for $65.42 \%$ of the total; The areas mainly concentrated in the regions of $8-15^{\circ}, 15-25^{\circ}, 25-35^{\circ}$, which accounted for $39.57 \%, 28.59 \%$, and $13.54 \%$ of the total, respectively, and the erosion level is concentrated on severe, violent and extremely violent intensity.

\section{Acknowledgements}

This study is supported by the National Natural Science Foundation of China (NSFC) (grant nos. 41771493 and 41101407); the Natural Science Foundation of Hubei Province (grant nos. 2014CFB377 and 2010CDZ005), China; Wuhan Youth Science and technology plan (Grant No. 2016070204010137) and self-determined research funds of CCNU from the colleges' basic research and operation of MOE (grant nos. CCNU15A02001). We are also grateful for the comments and contributions of the anonymous reviewers and the members of the editorial team.

\section{References}

[1] W. W. H and S. D. D, Predicting Rainfall Erosion Losses from Cropland East of the Rocky Mountains: A Guide for Soil and Water Conservation Planning. Washington D C: USDA, 1978.

[2] N. Vol., "A. GIS procedure for automatically calculating the USLE LS factor on topographically complex landscape units," Journal of Soil \& Water Conservation, vol. 51, pp. 427-433, 1996.

[3] R. K. G, F. G. R, W. G. A, and et al, Predicting Rainfall Erosion by Water: A Guide to Conservation Planning with the Revised Universal Soil Loss Equation (RUSLE). Washington D C: USDA, 1997.

[4] L. B. Y, Z. K. L, and X. Y, An Empirical Soil Loss Equation, ed. Beijing: Tsinghua Press, 2002, pp. 143-149.

[5] R. P. C. Morgan, J. N. Quinton, R. E. Smith, G. Govers, J. W. A. Poesen, K. Auerswald, et al., "The European Soil Erosion Model (EUROSEM): a dynamic approach for predicting sediment transport from fields and small catchments," Earth Surface Processes \& Landforms, vol. 23, pp. 527-544, 1998.

[6] A. P. J. De Roo, R. J. E. Offermans, and N. H. D. T. Cremers, "Lisem: A Single-Event, Physically Based Hydrological And Soil Erosion Model For Drainage Basins. Ii: Sensitivity Analysis, Validation And Application," Hydrological Processes, vol. 10, pp. 1119-1126, 2015.

[7] C. W. Rose, "A mathematical model of soil erosion and deposition process: I. Theory for a plane element," Soil Sci.soc.am.j, vol. 47, pp. 991-995, 1983.

[8] A. P. J. De Roo, "The Lisem Project: An Introduction," Hydrological Processes, vol. 10, pp. 1021-1025, 2015.

[9] M. K. Hazarika and K. Honda, "Estimation of soil erosion using Remote Sensing and GIS, its valuation and economic implications on agricultural production," Sustaining the Global Farm, pp. 1090-1063,2001.

[10] Z. Bu, J. Sun, and F. Zhou, "A study on quantitative remote sensing method of soil erosion and its application," Acta Pedologica Sinica, vol. 34, pp. 235-245, 1997.

[11] L. Yuechen, L. Chunxia, Z. Chunyong, and H. Jianhui, "Spatiotemporal Features of Soil and Water Loss in the Three Gorges Reservoir Areaof Chongqing," Acta Geographica Sinica, vol. 63, pp. 502-513, 2008.

[12] J. Wang, W. Cheng, Q. I. Shenglin, C. Zhou, W. Zhang, and C. Tong, "Sensitive evaluation and spatial analysis of soil and water loss based on USLE and GIS:Taking Taihang Mountain area of Hebei Province as an example," Geographical Research, vol. 33, pp. 614-624, 2014. 